\title{
Perception vs pain and beliefs about pain control and Type A behavior pattern in patients with chronic ischemia of lower extremities or with rheumatoid arthritis
}

This article was published in the following Dove Press journal: Journal of Pain Research

\author{
Monika Kadłubowska' \\ Ewelina Bąk' \\ Czesław Marcisz ${ }^{2}$ \\ Maria Kózka ${ }^{3}$ \\ Anna Michalik' \\ Jolanta Kolonko' \\ Bożena Krawczyk' \\ Dorota Dobrzyń-Matusiak ${ }^{4}$ \\ Zofia Kapusta-Nowak ${ }^{5}$ \\ 'University of Bielsko-Biała, \\ Department of Nursing, Faculty \\ of Health Sciences, Bielsko-Biała, \\ Poland; ${ }^{2}$ Medical University of \\ Silesia, Department of Gerontology \\ and Geriatric Nursing, School of \\ Health Sciences, Katowice, Poland; \\ ${ }^{3}$ Jagiellonian University Medical \\ College, Department of Clinical \\ Nursing, Institute of Nursing and \\ Midwifery, Faculty of Health Sciences, \\ Cracow, Poland; ${ }^{4}$ Medical University \\ of Silesia, Department of Nursing \\ Propaedeutics, School of Health \\ Sciences, Katowice, Poland; ${ }^{5}$ Medical \\ University of Silesia, Department of \\ Health Promotion and Community \\ Nursing, School of Health Sciences, \\ Katowice, Poland
}

Correspondence: Ewelina Bąk Faculty of Health Sciences, University of Bielsko-Biala, ul. Willowa 2, 43-309 Bielsko-Biala, Poland Tel +4833 8279198 Email ewelina.bak76@wp.pl

\begin{abstract}
Objective: The study aimed at determining the experience of pain taking into consideration beliefs about pain control, Type A behavior pattern and sociodemographic factors in patients with chronic ischemia of the lower extremities or with rheumatoid arthritis (RA).

Methods: The study enrolled 100 patients with peripheral arterial disease (PAD) and 100 patients with RA. The subjective sensation of pain was assessed using the Visual Analog Scale (VAS); beliefs about pain control were analyzed using the Beliefs about Pain Control Questionnaire (BPCQ), taking into consideration internal factors, the influence of physicians and accidental events (chance); and Type A behavior features (haste and competition) were analyzed using the Framingham Type A Scale. The multiple regression model was used to assess associations between the experienced pain and the BPCQ value, the Framingham Type A Scale and sociodemographic factors.
\end{abstract}

Results: The pain intensity degree was found to be comparable in patients with PAD and with RA. The median determined using the VAS was 5.75 in both of the studied groups. In patients with PAD, lower VAS values were associated with the BPCQ - internal factors $(P<0.05)$ whereas a higher VAS value was related to the BPCQ - physicians' influence $(P<0.001)$. In patients with RA, a higher VAS value was associated with BPCQ - physicians' influence $(P<0.05)$, disease duration $(P<0.05)$ and smoking cigarettes $(P<0.05)$.

Conclusion: Experiencing pain by patients with chronic ischemia of the lower extremities occurs at a moderate level and is beneficially connected with the internal factors and adversely connected with the external factors of beliefs about pain control. Patients with RA reported pain ailments of a moderate level in connection with the adverse influence of the external factors of beliefs about pain control, the duration of the disease and smoking cigarettes. Experiencing pain by patients with chronic ischemia of the lower extremities and RA does not seem to be related to Type A behavior.

Keywords: inflammatory process, atherosclerosis, discomfort, temperament, patients' beliefs about pain control

\section{Background}

Pain is a subjective phenomenon, a somatic-mental sensation, and the way it is perceived is affected by individual perception. ${ }^{1}$ The International Association for the Study of Pain describes pain as an individual experience - both sensory and emotional - accompanying the occurring or threatening tissue damage or only experienced and described by the patient as a pain sensation. ${ }^{2}$ A patient's mental reaction to chronic pain is shaped by a number of factors. The significance which the person experiencing pain 
assigns to the pain stimulus accompanying a chronic disease may greatly affect the pain sensation itself and may induce using various methods of coping with pain and various methods for regulating emotions. ${ }^{3}$ Psychological studies identify the role of behavioral, cognitive and emotional factors in modulating the experience of chronic pain and recommend a multidisciplinary approach, including a multimodal anti-pain scheme and nonpharmacological interventions. ${ }^{4}$ One of the factors influencing the perception of pain and the patient's view on his or her own ability to cope with it is the locus of control. ${ }^{5}$ The idea of the locus of control is related to general beliefs about what determines the effect of our actions and to a person's view of his or her ability to influence the health results and experiencing pain. ${ }^{6}$ The feeling of control over pain is an important determinant of experiencing pain ailments and the locus of pain control (internal, external or related to accidental events - chance) is related to beliefs about being able to cope with pain and to the approaches toward the treatment process. ${ }^{7,8}$

Chronic pain occurring in chronic ischemia of the lower extremities is the result of the atherosclerotic narrowing of the arteries which provide blood to the tissues of the lower extremities; this narrowing manifests itself by, among others, intermittent claudication and rest pain. These ailments intensify as the disease progresses and, as reported by Lyden and Joseph, ${ }^{9}$ they are difficult to bear. According to the study by Wiśniewska et al, ${ }^{10}$ the intensity of pain in patients with peripheral arterial disease (PAD) is high and patients are convinced about the influence of the external factors in pain control. Similarly in the case of the patients studied by Cwajda-Białasik et al, ${ }^{11}$ external factors intensified pain ailments. In the case of rheumatoid arthritis (RA), in turn, according to the study by Jia and Jackson, ${ }^{12}$ belief about internal control with the simultaneous reduction of external control influenced the reduction of pain ailments, in the sense of helplessness and of anxiety. Moreover, according to Boyden et al, ${ }^{13}$ persons with RA frequently experienced pain, even in remission periods, and factors such as depression, anxiety, sleep disturbances or catastrophic thinking increased the sensitivity to pain. The authors also draw attention not only to the inflammatory background of the disease but also to peripheral reasons (structural damage of the joints) or central reasons (abnormalities in the central nervous system conduction paths) which may influence the intensity of pain ailments and the necessity to develop pain treatment strategies. ${ }^{13}$

Another factor affecting the feeling of strength and readiness to change the current habits is Type A personality which determines certain behavior in difficult situations. Besides personality elements, this construct takes into consideration behavioral factors related to a person's behavior based on constant competition, a high level of ambition and engagement in achieving personal and professional goals under time pressure. ${ }^{14}$ The association between Type A personality (Type A behavior pattern [TABP]) and circulatory system diseases was the subject of numerous studies. Their authors pointed to the influence of psychosomatic factors in the formation and expression of coronary disease, the association between personality traits as well as TABP and arterial hypertension and even the duration of rehabilitation. ${ }^{15-18}$ Despite the fact that research related to Type A personality was related mainly to circulatory system diseases, attempts are being made to analyze this mental construct in the context of other diseases. Such studies were undertaken by Donisan et al, ${ }^{19}$ who proved higher quality of life, less intense sensation of pain ailments and lower activity of RA in patients with Type A personality. In other research, Keefe and Somers ${ }^{20}$ underline the necessity for further studies in the scope of the influence of psychological factors and broadly understood interventions in RA. The present study fits well within this scope.

The aim of the study was determining the experiencing of pain taking into consideration beliefs about pain control, TABP and sociodemographic factors in patients with chronic ischemia of the lower extremities or with RA.

\section{Materials and methods}

\section{The patients}

The study enrolled 100 patients with chronic ischemia of the lower extremities (PAD), including 26 women and 74

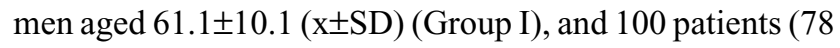
women and 22 men) with RA (Group II) aged 55.6 \pm 12.4 . Group I included inpatients of the Department of General and Vascular Surgery of the Regional Hospital in BielskoBiała. The patient inclusion criteria for the studies were a diagnosis of lower extremity ischemia stage II, III or IV according to Fontaine's classification, implemented conservative treatment and informed written consent for participation in the studies. The persons qualified for Group I were those selected out of 125 consecutively examined patients with PAD taking into consideration the inclusion criteria. The reason for the reduction of the number of patients qualified for further studies was a lack of consent from 14 patients and incomplete filling in of surveys by 11 patients. The patients were divided into two subgroups: patients with intermittent claudication (stage II according 
to Fontaine's classification) and those with rest pain (stage III and IV according to Fontaine's classification). Due to the small number of patients in stage IV according to Fontaine's classification ( 2 persons), these patients were considered together with those in stage III according to Fontaine's classification. The size of the analyzed PAD sample was selected basing on epidemiological data in Poland where the population of persons aged $50-70$ is 10 million, $5 \%$ of which have PAD. ${ }^{21}$ After considering the 0.05 significance level with a $5 \%$ maximum error, the minimum sample size was 73 persons.

The patients from Group II were selected out of 112 consecutive patients with RA treated at the Silesian Center for Rheumatology, Rehabilitation and Disability Prevention in Ustron. The patient inclusion criteria for the studies were a diagnosis of RA, implemented conservative treatment and informed written consent for participation in the studies. The reason for not considering 12 persons in further studies was a lack of consent from 11 persons and the resignation of 1 person during the course of the studies. Considering the fact that in Poland about $1 \%$ of the adult population suffer from RA, ${ }^{22}$ with the assumption that the maximum error is $2 \%$ and with a 0.05 significance level, the minimum sample size is estimated to be 96 persons.

The study was carried out in the period from December 2010 to January 2012 after obtaining the consent of the Bioethics Committee of the Beskidzka Regional Chamber of Physicians in Bielsko-Biala (consent no. 2010/11/30/6, 2011/03/17/6). The study was carried out in accordance with ethical standards of the Committee and with the 1964 Declaration of Helsinki.

\section{Method}

The method used among the studied patients was a diagnostic survey applying the Sociodemographic and Clinical Data Survey Questionnaire, the Beliefs about Pain Control Questionnaire (BPCQ), the Framingham Type A Scale and the Visual Analog Scale (VAS). Before commencement of the study the respondents were informed of their purpose, the voluntary participation and the possibility to withdraw from the study at any stage of their course. The survey questionnaires were filled in by the patients in the presence of the author conducting the research (MK). The time needed for filling in the survey was $25-30 \mathrm{~min}$.

\section{The demographic and clinical data questionnaire}

The questionnaire referring to demographic and clinical data included parameters such as: age, gender, marital status, place of residence, type of professional activity, smoking cigarettes, duration of disease and being a patient of the Vascular Outpatient Clinic or the Rheumatology Outpatient Clinic.

\section{The Beliefs about Pain Control Questionnaire}

The BPCQ was developed by S. Skevington, and the Polish adaptation has been developed by Juczyński. During the assessment of the reliability of the Polish version of the questionnaire, the achieved Cronbach $\alpha$ coefficient was 0.75 for the whole scale. The questionnaire has been translated and approved in Polish. ${ }^{23}$ It allows for becoming familiar with the locus of pain control which among others is responsible for undertaking or avoiding health-conducive behaviors. The questionnaire consists of 13 statements that form three subscales measuring the strength of individual beliefs about managing pain personally (internal factors - internality), through the influence of physicians (the power of other people - the so-called "powerful others") or through accidental events (as a result of chance). The questionnaire applies a 6-point Likert scale which the analyzed patient uses to assess the content of the provided opinions. A 1-point assessment indicates that the studied subject completely disagrees; 2 points indicate that the subject disagrees; 3 points that the subject rather disagrees; 4 points that the subject rather agrees; 5 points that the subject agrees; and 6 points indicate that the subject completely agrees. For each dimension of the locus of pain control a total score is calculated; the scope of points possible to obtain in reference to the internal control is 5-30 points and for the influence of physicians and accidental events is 4-24 points. A higher result reflects a stronger belief referring to the possibility to manage pain through the influence of a given factor. ${ }^{23}$

\section{Framingham Type A Scale}

The Type A Scale was developed by the Framingham Heart Study research group, and the Polish adaptation has been developed by Juczyński. The reliability of the Polish version of the questionnaire was Cronbach $\alpha=0.62$. The questionnaire has been translated and approved in Polish. ${ }^{23}$ The scale allows for becoming familiar with the personality features which not only contribute to the formation of cardiovascular diseases but also play a significant role in undertaking behaviors favorable to health and to the participation in treatment and rehabilitation. The scale consists of 10 statements, the first five of which refer to the characteristics and features typical for a given person, the next four refer to the feelings at the end of a day and the last statement refers to 
time pressure. Appropriate values (weights) are assigned to answers provided to statements. The scale includes two factors characterizing Type A: haste and competition. The general result of the scale is the mean value of all the assessments and it falls in the range of $0-1$. Results close to " 1 " indicate Type A behaviors, a sense of time pressure and a tendency to compete. Results close to " 0 " indicate the dominance of Type B behaviors, a lack of time pressure and a slight tendency to compete. ${ }^{23}$

\section{The Visual Analog Scale}

The VAS is used for the assessment of the pain intensity degree The patient uses a $10 \mathrm{~cm}$ long horizontal line to indicate the degree of pain intensity ranging between " 0 " (indicating "no pain") and "10" ("the strongest pain one can imagine" $){ }^{24}$

\section{Statistical analysis}

The statistical calculations were performed using Statistica v. 13 StatSoft Polska software. The level of statistical significance considered in all calculations was $P=0.05$. The type of distribution was checked for all analyzed variables using the Shapiro-Wilk $W$ test. The quantitative data were provided taking into consideration the median, the I and III quartiles and the minimum and maximum values. The statistical significance of differences among the patients with PAD was analyzed using the Mann-Whitney $U$ test. The reliability of the scale was defined by calculating the Cronbach $\alpha$ coefficient. The multiple regression analysis was carried out in order to investigate the associations of the sociodemographic factors, the clinical factors, the BPCQ scale and the Framingham Type A Scale with the subjective sensation of pain intensity.

\section{Results}

The sociodemographic and clinical characteristics of patients with PAD are presented in Table 1 . The prevailing gender in Group I was men. The prevailing sociodemographic groups were persons with vocational education, retired persons and married persons. Over half of the respondents smoked cigarettes. The patients reported a moderate level of intensity of pain ailments. The number of patients at stage II and III+IV according to Fontaine's classification was respectively 58 and 42 (Table 1).

The mean values in particular BPCQ domains did not demonstrate statistically significant differences between patients with PAD between stages II and III+IV according to Fontaine's classification. The respondents of both groups at a similar degree indicated pain control through internal factors, they believed in the influence of physicians in pain control and they considered pain control to depend on accidental events (chance) (Table 2).

Patients with stages II and III+IV of PAD according to Fontaine's classification were comparable in terms of the occurrence of Type A personality. Type A personality in both subgroups occurred at a similar level, similarly the factorhaste and competition (Table 3 ).

The prevailing sociodemographic groups among the patients with RA (Group II) were women, persons with secondary education and retired persons. The majority of the studied subjects inhabited urban areas and were married. The majority of the studied subjects did not smoke cigarettes. The

Table I Sociodemographic and clinical characteristics of the patients with peripheral arterial disease (PAD)

\begin{tabular}{|c|c|}
\hline \multicolumn{2}{|l|}{ Group I $(n=100)$} \\
\hline Analyzed parameter & Patients with PAD $(n=100)$ \\
\hline Age (years) & $60.5(55,67) / 27-88$ \\
\hline Gender: women/men & $26 / 74$ \\
\hline Education (n): primary/vocational/secondary/higher & $20 / 46 / 32 / 2$ \\
\hline Job (n): working/pension/retirement/unemployed/other & $20 / 27 / 48 / 3 / 2$ \\
\hline Place of residence $(n)$ : urban/rural area & $58 / 42$ \\
\hline Marital status (n): married/widow/single & $74 / 13 / 13$ \\
\hline You live $(n)$ : with family/alone & $91 / 9$ \\
\hline Smoking tobacco $(\mathrm{n})$ : nonsmoker/smoker & $65 / 35$ \\
\hline Including the number of cigarettes & $15(10,20) / 4-25$ \\
\hline Including the duration of smoking & $35(30,40) / 10-65$ \\
\hline Duration of disease (years) & $3(2,10) / 0.08-30$ \\
\hline $\begin{array}{l}\text { Frequency of followup appointments at the outpatient clinic (lack } / I \times \text { a month } / 3 \times \text { a month } / 6 \times \text { a month } / I \times \text { a year } / \\
\text { first time/lack of data) }\end{array}$ & $4 / 24 / 27 / 18 / 13 / 12 / 2$ \\
\hline Fontaine stage of PAD (II/III+IV) & $58 / 42$ \\
\hline Visual Analog Scale (score) & $5.75(4.75,7.5) / 0-10$ \\
\hline
\end{tabular}

Note: Data presented as median (interquartile range)/minimum-maximum, unless otherwise indicated. 
Table 2 Beliefs about Pain Control Questionnaire (BPCQ) in the patients with peripheral arterial disease (PAD)

\begin{tabular}{|c|c|c|c|c|}
\hline \multicolumn{5}{|l|}{ Patients with PAD } \\
\hline BPCQ & Together $(n=100)$ & Stage II of PAD ${ }^{a}(n=58)$ & Stage III+IV of PAD ${ }^{a}(n=42)$ & $P$-value \\
\hline Internal factors (score) & $18(14,21) / 5-30$ & $18(14,21) / 5-30$ & $17.5(|4,2|) / 5-30$ & $0.86 *$ \\
\hline Influence of physician (score) & $19(16,21) / 9-24$ & $18.5(16,21) / 9-24$ & $19(17,21) / 12-24$ & $0.42 *$ \\
\hline Accidental events (score) & $16(14,20) / 7-24$ & $16(13,20) 8-24$ & $17(14,20) / 7-24$ & $0.36 *$ \\
\hline
\end{tabular}

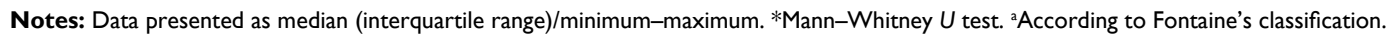

Table 3 Framingham Type A personality in the patients with peripheral arterial disease (PAD)

\begin{tabular}{|c|c|c|c|c|}
\hline \multicolumn{5}{|c|}{ Patients with PAD } \\
\hline Framingham & Together $(n=100)$ & Stage II of PAD $(n=58)$ & Stage III+IV of PAD $(n=42)$ & $P$-value \\
\hline Type A & $0.43(0.30,0.60) / 0-1$ & $0.43(0.30,0.60) / 0-0.9$ & $0.43(0.30,0.60) / 0-1$ & $0.6 I^{*}$ \\
\hline Haste & $0.47(0.33,0.60) / 0-1$ & $0.47(0.33,0.60) / 0-1$ & $0.4(0.27,0.67) / 0-1$ & $0.58 *$ \\
\hline Competition & $0.4(0.2,0.6) / 0-1$ & $0.4(0.2,0.6) / 0-0.8$ & $0.4(0.2,0.6) / 0-1$ & $0.58 *$ \\
\hline
\end{tabular}

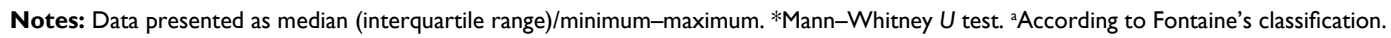

Table 4 Sociodemographic and clinical characteristics of the patients with rheumatoid arthritis (RA)

\begin{tabular}{|c|c|}
\hline \multicolumn{2}{|l|}{ Group II $(n=100)$} \\
\hline Analyzed parameter & Patients with RA $(n=100)$ \\
\hline Age (years) & $57(49,62) / 19-90$ \\
\hline Gender: women/men & $78 / 22$ \\
\hline Education (n): primary/vocational/secondary/higher & $9 / 29 / 55 / 7$ \\
\hline Job (n): working/pension/retirement/unemployed/other & $30 / 20 / 42 / 5 / 3$ \\
\hline Place of residence $(n):$ urban/rural area & $84 / 16$ \\
\hline Marital status $(\mathrm{n}):$ married/widow/single & $70 / 15 / 15$ \\
\hline You live $(n)$ : with family/alone & $85 / 15$ \\
\hline Smoking tobacco $(\mathrm{n})$ : nonsmoker/smoker & $86 / 14$ \\
\hline Including the number of cigarettes & $10(5,15) / 3-20$ \\
\hline Including the duration of smoking & $20(15,25) / 10-35$ \\
\hline Duration of disease (years) & $10(3,20) / 0.5-50$ \\
\hline Attending an outpatient clinic & 97 \\
\hline $\begin{array}{l}\text { Frequency of follow-up appointments at the outpatient clinic (lack/I } \times \text { a month } / 3 \times \text { a month } / 6 \times \text { a month } / I \times \text { a year } / \\
\text { first time/lack of data) }\end{array}$ & $0 / 3 \mid / 42 / 18 / 2 / 5 / 2$ \\
\hline Experiencing pain (especially in the evening/irrespectively of the time of day/other) & $15 / 74 / I I$ \\
\hline Visual Analog Scale (score) & $5.75(4.75,7) / 0.5-10$ \\
\hline
\end{tabular}

Note: Data presented as median (interquartile range)/minimum-maximum, unless otherwise indicated.

patients reported a moderate level of pain ailments, mostly "irrespectively of the time of day" (Table 4).

The point scores of the BPCQ components among patients with RA were comparable (Table 5).

Type A personality and the haste and competition factors among patients with RA proved to be comparable (Table 6).

In the multiple regression model the VAS value was considered as the dependent variable and the following elements were considered as independent variables: age, gender, education, smoking tobacco, duration of disease, BPCQ - internal factors, BPCQ - influence of physicians, BPCQ - accidental events (chance), Framingham Type A, Framingham - haste and Framingham - competition. In patients with PAD, lower VAS values were associated with the BPCQ - internal factors $(\beta=-0.24, P<0.05)$ whereas a higher VAS value was related to the BPCQ - physicians' influence $(\beta=0.34, P<0.001)$ (Table 7). The calculated $R^{2}$ determination coefficient $=0.217$ means that $21.7 \%$ of the level of the subjective sensation of pain intensity in patients with PAD is explained by this applied model; in the variance analysis for the VAS variable, $F=4.303$ 
Table 5 Beliefs about Pain Control Questionnaire (BPCQ) in the patients with rheumatoid arthritis (RA)

\begin{tabular}{|l|l|}
\hline BPCQ & Patients with RA (n=100) \\
\hline Internal factors (score) & $14(1 \mathrm{I}, 17) / 5-26$ \\
\hline Influence of physician (score) & $16(13,19) / 5-24$ \\
\hline Accidental events (score) & $15(12.5,18) / 7-24$ \\
\hline
\end{tabular}

Note: Data presented as median (interquartile range)/minimum-maximum.

Table 6 Framingham Type A personality in the patients with rheumatoid arthritis (RA)

\begin{tabular}{|l|l|}
\hline Framingham & Patients with RA (n=100) \\
\hline Type A & $0.5(0.33,0.63) / 0.10-0.87$ \\
\hline Haste & $0.47(0.40,0.60) / 0.07-0.93$ \\
\hline Competition & $0.4(0.2,0.8) / 0-1$ \\
\hline
\end{tabular}

Note: Data presented as median (interquartile range)/minimum-maximum.

Table 7 Multiple regression analysis in the patients with peripheral arterial disease (PAD)

\begin{tabular}{|l|l|l|l|l|}
\hline Patients with PAD \\
\hline $\begin{array}{l}\text { Dependent } \\
\text { variable }\end{array}$ & $\begin{array}{l}\text { Independent } \\
\text { variable }\end{array}$ & $\boldsymbol{\beta}$ & $\mathbf{b}$ & P-value \\
\hline VAS & Absolute term & & 40.14 & 0.0003 \\
\cline { 2 - 5 } & $\begin{array}{l}\text { BPCQ - influence } \\
\text { of physician }\end{array}$ & 0.34 & 1.83 & 0.0006 \\
\cline { 2 - 5 } & $\begin{array}{l}\text { BPCQ - internal } \\
\text { factors }\end{array}$ & -0.24 & -0.91 & 0.0159 \\
\cline { 2 - 5 } & Smoking tobacco & -0.19 & -7.84 & 0.0527 \\
\cline { 2 - 5 } & $\begin{array}{l}\text { Framingham - } \\
\text { haste }\end{array}$ & 0.38 & 32.27 & 0.0639 \\
\cline { 2 - 5 } & Primary education & -0.14 & -7.07 & 0.1434 \\
\cline { 2 - 5 } & $\begin{array}{l}\text { Framingham } \\
\text { Type A }\end{array}$ & -0.26 & -22.52 & 0.2199 \\
\hline
\end{tabular}

Abbreviations: b, slope coefficient; $\beta$, variable regression coefficient; BPCQ, Beliefs about Pain Control Questionnaire.

$(P<0.001)$. In patients with RA, a higher VAS value was associated with the BPCQ - physicians' influence $(\beta=0.17$, $P<0.05)$, the duration of the disease $(\beta=0.20, P<0.05)$ and smoking cigarettes $(\beta=0.18, P<0.05)$ (Table 8$)$. The calculated $\mathrm{R}^{2}$ determination coefficient $=0.128$ means that $12.8 \%$ of the level of the subjective sensation of pain intensity in patients with RA is explained by this applied model; in the variance analysis for the VAS variable, $F=2.765(P<0.05)$.

The Cronbach $\alpha$ value of the BPCQ and Framingham for our results were estimated at the following levels respectively: 0.76 and 0.78 for patients with PAD and 0.65 and 0.67 for patients with RA.
Table 8 Multiple regression analysis in the patients with rheumatoid arthritis (RA)

\begin{tabular}{|l|l|l|l|l|}
\hline \multicolumn{3}{|l|}{ Patients with RA } \\
\hline $\begin{array}{l}\text { Dependent } \\
\text { variable }\end{array}$ & $\begin{array}{l}\text { Independent } \\
\text { variable }\end{array}$ & $\boldsymbol{\beta}$ & $\mathbf{b}$ & $\boldsymbol{P}$-value \\
\hline \multirow{5}{*}{ VAS } & Absolute term & & 43.63 & $0.000 \mathrm{I}$ \\
\cline { 2 - 5 } & $\begin{array}{l}\text { BPCQ - influence } \\
\text { of physician }\end{array}$ & 0.17 & 0.74 & 0.0443 \\
\cline { 2 - 5 } & Duration of disease & 0.20 & 0.36 & $0.043 \mathrm{I}$ \\
\cline { 2 - 5 } & Smoking tobacco & 0.18 & 10.63 & $0.020 \mathrm{I}$ \\
\cline { 2 - 5 } & Primary education & 0.14 & 9.94 & 0.1591 \\
\cline { 2 - 5 } & $\begin{array}{l}\text { BPCQ - internal } \\
\text { factors }\end{array}$ & -0.10 & -0.45 & 0.3159 \\
\hline
\end{tabular}

Abbreviations: b, slope coefficient; $\beta$, variable regression coefficient; BPCQ, Beliefs about Pain Control Questionnaire; VAS, Visual Analog Scale.

\section{Discussion}

The pain ailments in the course of chronic ischemia of the lower extremities are manifested by intermittent claudication and rest pain. They are the response to the progressing atherosclerotic process which is the effect of pathogenic mechanisms that include among others inflammatory processes, oxidative stress, increased coagulation and microcirculation disorders. This atherosclerotic process results in impaired blood flow and ischemia. ${ }^{25}$ The elements underlined in the progression of the disease are the influence of the lifestyle on the condition of the vascular endothelium and the participation of inflammatory biomarkers in case of the co-occurrence of such chronic diseases as diabetes. ${ }^{25,26}$ Patients with chronic ischemia of the lower extremities experience pain which, along with the progression of the disease, becomes difficult to manage and is the cause of great suffering. In our own studies the patients with chronic ischemia of the lower extremities assessed the level of experienced pain ailments as moderate. Similar results were obtained by other researchers dealing with this problem. ${ }^{27}$ These researchers also pointed to the effect of chronic pain on social functioning in the form of difficulties with locomotion, difficulties in performing household activities, professional duties and driving a car, especially in the group of men. Other researchers, in turn, emphasized the associations between the acceptance of pain ailments and emotional and physical functioning of patients with chronic pain. ${ }^{28}$

The pain ailments related to RA are associated with a state of inflammation of an autoimmune background which manifests itself by joint movement disorders. ${ }^{29}$ Some patients additionally experience noninflammatory factors such as sleep disturbance and general fatigue which significantly affect the sensation of pain ailments in these patients. ${ }^{30} \mathrm{In}$ our own studies, patients with RA reported the occurrence 
of moderately intense pain ailments, mostly "irrespectively of the time of day." Moderate intensity of pain ailments was also observed in the study by Bączyk and Kozłowska, ${ }^{31}$ whereas strong pain in the course of RA was experienced by patients studied by Purabdollah et al. ${ }^{32}$ In the multiple regression analysis we have demonstrated that the duration of the disease and smoking cigarettes could intensify the perception of pain ailments in patients with RA. Studies by other authors suggested the influence of nicotine on the progression of the disease and the intensification of pain sensations. ${ }^{33,34}$ Other studies, in turn, have not demonstrated associations between experiencing pain coexisting with RA with smoking cigarettes or with the duration of the disease. ${ }^{31,35}$

The perception of pain is, to a great degree, associated with psychological factors which shape the patient's reactions to pain and, as a consequence, determine the intensity of his or her suffering. Psychological factors also play a significant role in the process of adaptation to the disease, especially to a chronic one accompanied by pain. A significant determinant affecting the possibility to cope with a chronic disease and the occurring pain is the feeling of the locus of control over the course of the disease and the pain. The internal or external locus of control affects the assessment of the danger degree and the adaptation to the new situation. ${ }^{36}$ In our own studies, patients with chronic ischemia of the lower extremities were classified into three types of control locus: internal, external and accidental (chance). In these types of control locus, the point scores proved to be comparable with the tendency for slightly higher scores in the scope of the physician's influence on pain control. It has to be noticed that these values did not demonstrate significant differences between stages II and III+IV of PAD according to Fontaine's classification. Wiśniewska et $\mathrm{al}^{10}$ demonstrated that patients with chronic ischemia of the lower extremities achieved the highest point score in the scope of the factors describing the influence of physicians and of the medical care on pain control. They assigned slightly lower significance to internal control and the smallest significance to the influence of chance. The studied subjects were convinced that without medical aid they will not be able to reduce the sensation of pain. Simultaneously, along with the increase of pain intensity, belief about the influence of medical care on pain control decreased and belief about internal control increased. ${ }^{10}$ Another study revealed that patients with chronic constant ischemic pain of the lower extremities more frequently passively succumbed to the disease, they manifested the locus of pain control mainly in external factors and associated relief in suffering with the help of the medical staff and the therapy proposed by that staff. ${ }^{11}$
In our own studies, patients with RA were, to a similar degree, convinced that pain control is associated with internal factors, accidental events (chance) and the physician's influence. The paper by Cabak et $\mathrm{al}^{8}$ indicates that out of the three pain control perception factors the ones dominating among patients with RA are the external factor and an accidental event factor. These results may prove the helplessness of patients toward pain ailments and a lack of readiness for taking responsibility in attempts to reduce pain. ${ }^{8}$ Arraras et $\mathrm{al}^{5}$ pointed to the importance attributed to the locus of pain control in modulating pain sensations, influencing mood and in the readiness to undertake actions. Moreover, they noticed a relationship between negative coping with pain, a lower internal sense of control and worse mood. Anxiety and depression, with the simultaneous lack of coping and lower internal locus of pain control, contribute to the intensification of mood disorders. Moreover, due to the emerging helplessness, patients do not adjust to recommendations and do not take an active role in managing their pain. This is a kind of a vicious circle which may cause worse adaptation to the disease and significantly affect the deterioration of quality of life. ${ }^{5}$ A strong internal locus of health control, in turn, reduces the risk of depression due to chronic pain. Above this, patients with a strong external sense of control are more downhearted and have got a worse sense of quality of life compared to patients with an internal locus of health control. A low quality of life is associated with a lack of sense of control and a lack of certainty related to an improvement in terms of the experienced pain ailments. ${ }^{4}$ In this context, the elements which gain high significance are medical interventions encouraging to actively cope with pain and to strengthen the internal locus of control as well as early treatment of depression which intensifies the perception of chronic pain. ${ }^{4,5}$ The importance of psychological support supplementing therapy is also underlined by Cwajda-Białasik et al, ${ }^{11}$ pursuant to the holistic approach to the patient during the therapeutic process.

In studies related to TABP and the haste and competition components it was found that both studied groups of patients proved to be comparable. In the multiple regression model, the values of Type A variables did not demonstrate associations with the degree of the experienced pain both in patients with PAD and with RA. The review of literature shows that few studies included the assessment of Type A behavior in connection with RA. However, the influence of this type of personality on the disease activity and on quality of life was noticed, ${ }^{19,37}$ whereas numerous studies rather emphasized the role of personality-related factors in the etiology of the 
diseases of the circulatory system. ${ }^{16,17}$ There are also voices which negate the significant influence of TABP on the formation of circulatory system diseases. ${ }^{38}$ Some authors indicate a shorter duration of hospitalization and rehabilitation in patients demonstrating this mental construct. ${ }^{18}$ It may be suspected that this is related to the feeling (which is typical for Type A personality) that a lot depends on the patient's own activity. Therefore, when faced with a lack of control over the new situation the patient may experience helplessness and a sense of hopelessness sometimes manifested as hostility and aggression. ${ }^{39}$ In problematic situations, persons with TABP more frequently demonstrate anger and devote themselves completely to work to forget about the problem; they are also less likely to identify family members as important persons in the social network surrounding them. ${ }^{40}$ The behavioral mechanisms related to adverse health behaviors mediate between the psychosocial conditions and the development of the disease. Therefore, the dependency between TABP and the occurrence and effects of treatment is of direct and indirect nature - through the pathophysiological mechanisms of other risk factors. Knowledge related to TABP may play a significant role in secondary prevention, as this type of behavior may change and reducing its effect beneficially affects the treatment results.

\section{Conclusion}

1. Experiencing pain by patients with chronic ischemia of the lower extremities occurs at a moderate level and is beneficially connected with the internal factors and adversely connected with the external factors of beliefs about pain control.

2. Patients with RA reported pain ailments of a moderate level in connection with the adverse influence of the external factor of beliefs related to pain control, the duration of the disease and smoking cigarettes.

3. Experiencing pain by patients with chronic ischemia of the lower extremities and RA does not seem to be related to Type A behavior.

\section{Disclosure}

The authors report no conflicts of interest in this work.

\section{References}

1. Twycross R. Factors involved in difficult-to-manage pain. Polska Medycyna Paliatywna. 2008;4(1):28-47.

2. International Association for the Study of PainMerskey H, Bonica J, Carmon A. Subcommitte on taxonomy of pain terms: a list with definitions and notes on usage. Pain. 1979;6:249-252.

3. Büssing A, Ostermann T, Neugebauer EA, Heusser P. Adaptive coping strategies in patients with chronic pain conditions and their interpretation of disease. BMC Public Health. 2010;10:507.
4. Wong HJ, Anitescu M. The role of health locus of control in evaluating depression and other comorbidities in patients with chronic pain conditions, a cross-sectional study. Pain Pract. 2017;17(1):52-61.

5. Arraras JI, Wright SJ, Jusue G, Tejedor M, Calvo JI. Coping style, locus of control, psychological distress and pain-related behaviours in cancer and other diseases. Psychol Health Med. 2002;7(2):181-187.

6. Cross MJ, March LM, Lapsley HM, Byrne E, Brooks PM. Patient selfefficacy and health locus of control: relationships with health status and arthritis-related expenditure. Rheumatol. 2006;45(1):92-96.

7. Cybulski M, Cybulski L, Krajewska-Kulak E, Cwalina U. Illness acceptance, pain perception and expectations for physicians of the elderly in Poland. BMC Geriatr. 2017;17(1):46.

8. Cabak A, Wasilewski L, Zdrodowska A, Tomaszewski P. Pain control in patients with chronic back pain syndrome. Ortopedia Traumatologia Rehabilitacja. 2011;13(4):361-368.

9. Lyden SP, Joseph D. The clinical presentation of peripheral arterial disease and guidance for early recognition. Cleve Clin J Med. 2006;73(suppl 4):S15-S21.

10. Wiśniewska A, Szewczyk MT, Cwajda-Białasik J, Cierzniakowska $\mathrm{K}$, Jawień A. Beliefs about pain control in patients with a chronic ischemia of lower limb. Piele gniarstwo Chirurgiczne i Angiologiczne. 2009;3:113-121.

11. Cwajda-Białasik J, Szewczyk MT, Mościcka P, Cierzniakowska K. The locus of pain control in patients with lower limb ulcerations. $J$ Clin Nurs. 2012;21(23-24):3346-3351.

12. Jia X, Jackson T. Pain beliefs and problems in functioning among people with arthritis: a meta-analytic review. J Behav Med. 2016;39(5): 735-756.

13. Boyden SD, Hossain IN, Wohlfahrt A, Lee YC. Non-inflammatory causes of pain in patients with rheumatoid arthritis. Curr Rheumatol Rep. 2016;18(6):30.

14. Friedman M, Rossenman R. Association of specific overt behavior pattern with blood and cardiovascular findings. $\mathrm{J} \mathrm{Am} \mathrm{Med} \mathrm{Assoc.}$ 1959;169(12):1286-1296

15. Rozanski A, Blumenthal JA, Kaplan J. Impact of psychological factors on the pathogenesis of cardiovascular disease and implications for therapy. Circulation. 1999;99(16):2192-2217.

16. Allan R. John Hunter: early association of Type A behavior with cardiac mortality. Am J Cardiol. 2014;114(1):148-150.

17. Al-Asadi N. Type A behaviour pattern: is it a risk factor for hypertension? East Mediterr Health J. 2010;16(7):740-745.

18. Harunobu U, Yusuke N, Usui H, Nishida Y. Type A behavior pattern shortens length of stay in comprehensive rehabilitation units. $J$ Phys Ther Sci. 2015;27(1):183-185.

19. Donisan T, Bojincă VC, Dobrin MA, et al. The relationship between disease activity, quality of life, and personality types in rheumatoid arthritis and ankylosing spondylitis patients. Clin Rheumatol. 2017;36(7): 1511-1519.

20. Keefe FJ, Somers TJ. Psychological approaches to understanding and treating arthritis pain. Nat Rev Rheumatol. 2010;6(4):210-216.

21. Noszczyk W, Andziak P. Przewlekłe niedokrwienie kończyn dolnych [Chronic ischemia of the lower extremities]. W [In]: Noszczyk W, editor. Chirurgia tętnic i żył obwodowych. [Surgery of peripheral veins and arteries.] Warszawa: PZWL; 2007:563-595. Polish.

22. Tłustochowicz W, Brzosko M, Filipowicz-Sosnowska A, et al. Stanowisko Zespołu Ekspertów Konsultanta Krajowego ds. Reumatologii w sprawie diagnostyki i terapii reumatoidalnego zapalenia stawów. [The Opinion of the Team of Experts of the National Consultant on Rheumatology regarding the diagnostics and therapy of rheumatoid arthritis]. Reumatologia. 2008;46(3):111-114. Polish

23. Juczyński Z. Narzędzia pomiaru w promocji i psychologii zdrowia. [Measurement tools in the promotion and psychology of health.]. Warszawa, Pracownia Testów Psychologicznych sp. z o.o.; 2009. Polish.

24. Dobrogowski J, Wordliczek J. Kliniczna ocena i postępowanie terapeutyczne w wybranych zespołach bólu ostrego i przewlekłego. [Clinical assessment and therapeutic procedure in selected acute and chronic pain syndromes.] W [In]: Wordliczek J, Dobrogowski J, editors, Leczenie bólu. [The Treatment of Pain] Warszawa: PZWL; 2007:171-181. Polish. 
25. Brodziak A. Pathogenesis. Prevention and treatment of peripheral artery disease. Ann Acad Med Stetin. 2014;68(6):430-448.

26. Bąk E, Marcisz C, Kadłubowska M, et al. Independent factors of changes of ankle-brachial index in peripheral arterial occlusive disease in elderly patients with or without diabetes. Int J Environ Res Public Health. 2016;13(11):1103.

27. Ponczek D, Piotrowska K, Felsmann M, Humańska M. Perception of pain in patient with chronic limb ischemia. Pielegniarstwo Chirurgiczne i Angiologiczne. 2012;1:13-19.

28. Mccracken LM, Vowles KE, Eccleston C. Acceptance of chronic pain: component analysis and a revised assessment method. Pain. 2004;107(1-2):159-166.

29. Siegel P, Tencza M, Apodaca B, Poole JL. Effectiveness of occupational therapy interventions for adults with rheumatoid arthritis: a systematic review. Am J Occup Ther. 2017;71(1):1.

30. Lee YC, Frits ML, Iannaccone CK, et al. Subgrouping of patients with rheumatoid arthritis based on pain, fatigue, inflammation, and psychosocial factors. Arthritis Rheumatol. 2014;66(8):2006-2014.

31. Bą czyk G, Kozłowska K. The role of demographic and clinical variables in assessing the quality of life of outpatients with rheumatoid arthritis. Arch Med Sci. 2018;14(5):1070-1079.

32. Purabdollah M, Lakdizaji S, Rahmani A. Relationship between sleep, pain and inflammatory markers in patients with rheumatoid arthritis. $J$ Caring Sci. 2017;6(3):249-255.
33. Roelsgaard IK, Thomsen T, Østergaard M, et al. The effect of an intensive smoking cessation intervention on disease activity in patients with rheumatoid arthritis: study protocol for a randomised controlled trial. Trials. 2017;18(1):570.

34. Rydell E, Forslind K, Nilsson JÅ, Jacobsson LTH, Turesson C. Smoking, body mass index, disease activity, and the risk of rapid radiographic progression in patients with early rheumatoid arthritis. Arthritis Res Ther. 2018;20(1):82.

35. Andersson ML, Bergman S, Söderlin MK. The effect of stopping smoking on disease activity in rheumatoid arthritis (RA). Data from BARFOT, a multicenter study of early RA. Open Rheumatol J. 2012;6:303-309.

36. Juczyński Z. Perceived personal control and coping strategies in chronic pain patients. Sztuka Leczenia. 2001;7(2):9-16.

37. Potts MK, Katz BP, Brandt KD. Prevalence and correlates of the type A behavior pattern in patients with rheumatoid arthritis. Psychol Rep. 1985;57(3 Pt 1):699-706.

38. Šmigelskas K, Žemaitienė N, Julkunen J, Kauhanen J. Type A behavior pattern is not a predictor of premature mortality. Int J Behav Med.2015;22(2): 161-169.

39. Ogińska-Bulik N. Type D-personality and prevalance of somatic diseases. Sztuka Leczenia. 2004;10(2):9-16.

40. Vroege JA, Aaronson NK. Type A behavior and social support among employed women. Behav Med. 1994;19(4):169-173.

\section{Journal of Pain Research}

\section{Publish your work in this journal}

The Journal of Pain Research is an international, peer reviewed, open access, online journal that welcomes laboratory and clinical findings in the fields of pain research and the prevention and management of pain. Original research, reviews, symposium reports, hypothesis formation and commentaries are all considered for publication.

\section{Dovepress}

The manuscript management system is completely online and includes a very quick and fair peer-review system, which is all easy to use. Visit http://www.dovepress.com/testimonials.php to read real quotes from published authors. 